\title{
Imagens Efêmeras: sociedade de controle, sexualidade, performatividade e educação*
}

\section{Ephemeral Images: control society, sexuality, performativity and education}

\begin{abstract}
Resumo:
Neste texto nos ocupamos da ocorrência de um vídeo 'pornô' criado a partir de telefones celulares por alunos de uma escola pública de ensino medio no interior do Estado do Espírito Santo. Ao abordar o episodio, buscamos fazer dele um caso de pensamento em meio ao qual problematizamos a educação escolar em suas relaçôes com os novos dispositivos de produção e circulação de imagens, com as redes sociotécnicas de comunicação, com as formas de subjetividade contemporâneas e com as moralidades que se constituem nas sociedades de controle. Que pistas essa produção e circulação de vídeos nos sugerem para pensar a educação que oferecemos, a educação que os jovens almejam e uma outra educação possível nas contingências das sociedades pós-mídia? Como pensar essa produção no contexto das possibilidades/prescrições inscritas nos artefatos técnicos e nos modos de auto-apresentação dos indivíduos e grupos que as novas mídias favorecem? Nesse caminho de pensamento, em que tivemos com principais intercessores Deleuze, Flusser, Foucault, Gadelha, Gonçalves e Head, apontamos para a necessidade de analisar se continuamos promovendo a regulação e a normalização da vida, despotencializando os jovens com o objetivo de fabricar subjetividades submissas e corpos produtivos como requer o capitalismo, ainda que não nos demos conta disso por termos naturalizado determinadas práticas e discursos. Dessa forma, e de modo a tentar evitar atitudes extremadas e possivelmente auto-destrutivas por parte de nossos alunos, propomos, ao compreender seus anseios por nossos alunos, propomos, ao compreender seus anseios por de fuga afirmativas que engendrem outros modos de existir Palavras-chave: Dispositivos móveis. Imagens. Controle. Criação. Educação.
\end{abstract}

\section{Abstract:}

In this text we are concerned about the occurrence of a 'porn' video created from cell phones by students in a public high school in the State of Espírito Santo. Studding the episode, we look for to make it a case of thought in which we problematize the school education in their relations with new devices of production and circulation of images, with the socio-technical networks of communication, with the contemporary forms of subjectivity and the moralities that are in the societies of control. What clues does that production and circulation of videos suggest us to think of the education we offer, the education that the young people want and another possible education in the contingencies of the post-media society? How to think about this production in the context of possibilities/prescriptions included in the technical artifacts and ways of self-presentation of individuals and groups who are favor by the new media? In this way of thinking, we had as major intercessors Deleuze, Flusser, Foucault, Gadelha, Gonçalves and Head, pointed to the need to analyze whether to continue promoting the regulation and normalization of life, unpowering the young people with the goal of making submissive subjectivities and productive bodies as required by capitalism, even though we did not realize that because we have naturalized certain practices and discourses. In this way, and in a way of trying to avoid extreme attitudes and possibly self-destructive by our students, we propose, when we understood their aspirations for freedom and creation spaces, that we trace lines of affirmative escape that engender other ways to exist.

Key-words: Mobile devices. Images. Control. Creation. Education.

SOARES, Conceição; MAIA, Vanessa. Imagens Efêmeras: sociedade de controle, sexualidade, performatividade e educação. Informática na Educação: teoria \& prática, Porto Alegre, v. 13, n. 2 , p. $80-89$, jul./dez. 2010

\section{Conceição Soares}

Universidade do Estado do Rio de Janeiro

Vanessa Maia

Universidade Federal do Espírito Santo

\section{Introdução}

D e várias formas a chamada sociedade da comunicação vem sendo vivenciada nos múltiplos contextos de nossas vidas cotidianas. É perceptível que a ambiência comunicacional instituída pela agenda das mensagens midiáticas e pelos modos de subjetivação e de sociabilidade que as tecnologias da informação - em constantes e aceleradas transformações engendram vêm produzindo desordenamentos e descentramentos culturais que atingem, entre outras, a cena doméstica e a cena escolar, provocando certo desalento em pais e professores, manifesto em expressões tais como as crianças de hoje sabem mais que os adultos e sabem de coisas que não são para sua idade.

Nossas pesquisas têm demonstrando que, independente das escolas estarem ou não equipadas com os novos artefatos tecnológicos e do que prescrevem as diretrizes curriculares, em grande parte delas, os meios, as mensagens, os artefatos e as lógicas comunicacionais, autorizados ou não, entram pelas mãos ou por

\footnotetext{
* Uma versão inicial dessa discussão foi apresentada no XXXIII Congresso Brasileiro de Ciências da Comunicação, realizado em setembro de 2010, em Caxias do Sul.
} 
meio de experiências vividas pelos estudantes em outros contextos de suas vidas. As desordens e os descentramentos provocados no dia a dia pelos usos que eles fazem dessas tecnologias, por mais banais que possam parecer, vêm embaçando fronteiras de saber e de poder. $\mathrm{E}$, como adverte Jenkins (2009, p. 45), "[...] quando as pessoas assumem o controle das mídias, os resultados podem ser maravilhosamente criativos; podem ser também uma má notícia para todos os envolvidos [...]".

Neste texto, nos ocupamos da produção e veiculação de um vídeo 'pornô' produzido a partir de telefones celulares por alunos de uma escola pública de ensino médio em uma cidade no interior do Estado do Espírito Santo. Ao abordar esse caso, buscamos fazer dele um caso de pensamento, ou seja, mais do que explicar, relacionar causas e efeitos ou restituir a verdade dos fatos, desejamos problematizar, fazer problemas que nos possibilitem pensar os dilemas e os desafios que todos aqueles envolvidos com a educação enfrentam nas contingências da contemporaneidade.

\section{Um Caso Para se Pensar}

Há cerca de um mês, três vídeos com cenas de sexo explícito viraram 'febre' entre os alunos da escola $[\ldots]^{1}$, em Aracruz. E o que chama mais atenção nessa história é que, ente os "atores", estão três meninas e um menino, menores de idade e alunos da escola. Além disso, as imagens foram gravadas e espalhadas pelos próprios estudantes, por meio de seus celulares. (ADOLESCENTES..., 2009, p. 9)

Quando essa notícia, referente ao acontecimento ${ }^{2}$ que se engendrou em uma escola pública estadual de ensino médio, chegou ao conhecimento do grande público os vídeos já tinham caído nas redes. Primeiro, chegaram à comunidade escolar e adjacências, transmitidos de celular a celular, via bluetooth. Depois, foram disseminados pela internet, postados no site de relacionamentos Orkut em uma das comunidades da escola.

1 Optamos por omitir o nome da escola, preservando-a, uma vez que essa informação não é relevante na nossa abordagem.

2 Entendemos por acontecimento o imprevisível, aquilo que nos arranca do rumo e desloca nossas certezas.
Embora os vídeos já estivessem circulando há cerca de dois meses entre os adolescentes, distribuídos em novas e colaborativas mídias (celular e internet), foi no momento em que a notícia passou a figurar nos telejornais locais e no maior jornal impresso do estado que instituições sociais capixabas, como a Vara da Infância e da Juventude, o Conselho Tutelar, o Núcleo de Repressão aos Crimes Eletrônicos, o Ministério Público Estadual, as famílias e os especialistas, convocados pela grande imprensa, arvoraram-se a explicar, justificar e anunciar providências em relação ao episódio. O caso dos vídeos pornográficos, que, segundo consta, teriam sido feitos e distribuídos pelos próprios adolescentes através de celulares, foi denunciado pela mãe de uma estudante de 14 anos que havia recebido os filmes. Os pais dos alunos envolvidos foram ouvidos pelo ConseIho Tutelar e o caso analisado pelo Ministério Público Estadual.

A escola, procurada pela imprensa local, declarou que iria proibir o uso de aparelhos celular em suas dependências, além de intensificar os programas que visam repassar aos alunos questões de ética, de valores e informações sobre os direitos e os deveres dos estudantes, conforme assegurou a então secretária de Educação do estado.

Enquanto as autoridades, frente à repercussão da notícia, anunciavam medidas cabíveis que iam da apuração da responsabilidade da escola, passando pela investigação de crimes e ofensa à honra na internet, até a punição aos pais, uma das alunas, protagonista das cenas, afirmou simplesmente: Eu fiz porque quis e todo mundo gostou de ver.

Em meio à perplexidade de uns, à indignação de outros, à indiferença irônica de alguns e à curiosidade de muitos, como professoraspesquisadoras de cursos de Pedagogia e de Jornalismo, fomos instigadas a problematizar esse evento, fazendo dele um caso de pensamento para discutir a educação na contemporaneidade. Dessa forma, partimos desse episódio não para descobrir o que realmente aconteceu e identificar os responsáveis, mas para pensar dilemas, possibilidades e possíveis para a educação escolar nesses tempos chamados de pós-modernos. Optando por esse caminho, não analisamos os vídeos nem julgamos os alunos atores/autores tomados, por alguns, como sujeitos de livre arbítrio e de escolhas individuais, morais, éticas e estéticas descontextualizadas 
do espaçotempo em que habitam. O que nos interessa nesse recorte é discutir a educação escolar em suas relações com os novos dispositivos de produção e circulação de imagens, com as redes sociotécnicas de comunicação, com as formas de subjetividade contemporâneas e também com as moralidades que se constituem na sociedade de controle.

Que pistas, indícios e sinais (GINSBURG, 1989) essa produção e circulação de vídeos pornôs, realizados por adolescentes, nos apontam para pensar a educação que oferecemos, a educação que os jovens almejam e uma outra educação possível na contingência da sociedade pós-mídia (GUATTARI, 2000)? Como pensar essa produção no contexto da sociedade de controle (DELEUZE, 1992), das possibilidades/prescrições inscritas nos artefatos técnicos (FLUSSER, 2002) e nos modos de auto-apresentação dos indivíduos e grupos que as novas mídias favorecem (GONÇALVES; HEAD, 2009)? Na tentativa de animar essa discussão, vamos nos valer ainda de nossas conversações com adolescentes que estudam em outras escolas públicas do estado, realizadas nos contextos de outras pesquisas que desenvolvemos.

Para começar esse caminho de pensamento, a primeira questão que gostaríamos de colocar é: estaríamos produzindo uma e sendo produzidos em meio a uma forma de controle que se exerce pela lógica da visibilidade total? $\mathrm{E}$, ainda assim, nos julgamos mais livres do que nunca porque acreditamos que fazemos 0 que queremos impunemente num mundo em que tudo é permitido e no qual nada pode nos intimidar? Deixamos de ser um número e um nome e viramos um arquivo de imagem no $\mathrm{PC}$, num site de relacionamentos qualquer ou no celular de alguém? Deixamos de ser espírito, alma, mente e consciência para nos tornarmos fluxos efêmeros, etéreos e incorpóreos? Que tipo de sociedade, de subjetividades e de relações sociais estamos criando para nós mesmos?

\section{Deleuze e a Sociedade de Controle}

Em seus estudos sobre a sociedade de controle, Gilles Deleuze (1992) propõe que uma nova lógica de subjetivação, o controle contí- nuo, estaria substituindo a disciplinarização. Um das facetas desse modo de controle é a hiper-vigilância a céu aberto, que se dá, entre outras tecnologias, pela presença de câmeras de vídeo em todos os lugares. Elas estão nas ruas, nos edifícios, nas escolas, na intimidade dos lares, enfim, em diversos espaços públicos e privados (será que ainda existe essa distinção?), por meio de vários aparelhos/dispositivos tecnológicos como câmeras digitais, celulares, radares, sensores e computadores. Esses dispositivos co-engendram, simultaneamente e em articulação com as mídias de massa e outros agenciamentos, atitudes como o exibicionismo e o voyeurismo, em meio a uma lógica de uma visibilidade total. Enunciados como sou visto logo existo e vamos dar uma espiadinha contribuem, em uma combinatória com outras exigências, para a constituição do complexo coquetel que constitui as subjetividades contemporâneas.

Nesse contexto, entendemos que as teletelas não são janelas através das quais temos acesso à realidade, mas que elas produzem realidades. Nem espelhos, nem representações simbólicas, nem verdadeiras, nem falsas, nem boas, nem más por si mesmas, apenas outras realidades. Mas, que realidades estamos criando com elas?

A questão que pretendemos problematizar não passa pela busca de segurança pública e privada, nem pelo olho de uma autoridade central que vigia e pune, nem pela substituição de uma suposta verdadeira realidade por signos, por imagens, pela ilusão ou por simulacros e/ ou simulações, mas sim pelas realidades que estamos criando. Estaríamos inventando, instituindo, experimentando, compartilhando, enfim, colaborando e nos tornando cúmplices, vítimas e executores do controle total numa sociedade em que todos controlam todos?

Nesses modos de vigiar e punir contemporâneos, o controle se faz por modulação e visibilidade e a punição pela exclusão, ou como diria Bauman (2008), ao analisar a mensagem sub-reptícia dos realyts shows do tipo Big Brother, pela iminente eliminação. Com efeito, o que mais nos ameaça e intimida nesses tempos pós-modernos é ser out, estar off e, pior ainda, sair mal na fita e acabar pagando mico no youtube, nas vídeocacetadas, nos orkutes e msn's alheios ou em qualquer outra telinha ou telão da vida, sempre expostos à impiedosa avaliação dos outros, agora transformados 
em nossos públicos e, ao mesmo tempo, em nossos gestores.

Estamos sempre expostos, hiper-expostos, e vamos nos constituindo em meio às intermináveis modulações, com suas constantes e cambiantes exigências, desejosos de estar sempre bem na fita. Precisamos estar com tudo em cima: bonitos, jovens, felizes, por dentro da moda, com o corpo perfeito, com os cabelos domados, em dia com as novidades, com as gírias, com os points. A ordem é ser feliz e gozar a vida, em todos e com todos os sentidos. Além de nos produzirmos nas freqüências moduladas da vida, precisamos mostrar isso aos outros, ou seja, provar que estamos fazendo o dever de casa, que estamos em dia com as expectativas sociais e que, por isso, estamos felizes, sempre felizes. Afinal, a exigência está colocada em toda parte: SORRIA, VOCÊ ESTÁ SENDO FILMADO!

Conforme Deleuze (1992), Foucault mostrou que as sociedades disciplinares dos séculos XVIII e XIX atingiram seu apogeu no início do século $X X$, procedendo à organização dos grandes meios de confinamento. Nessa lógica de controle, o indivíduo não cessava de passar de um espaço fechado a outro, cada um com suas leis: primeiro a família, depois a escola, mais tarde a fábrica, de vez em quando o hospital e eventualmente a prisão, tida como o meio de confinamento por excelência. Nessas condições, as pessoas eram moldadas.

Nas sociedades disciplinares buscava-se produzir discursivamente subjetividades desejáveis e a docilização dos corpos em ambientes fechados, cuja principal tecnologia era o panopticon. As pessoas eram vigiadas o tempo todo por alguém que via sem ser visto. Com medo da punição, todos agiriam conforme a lei e a ordem instituída pela autoridade do lugar. O principal objetivo da punição não era recuperar o desviante, mas sim enquadrar os demais, desestimulando aqueles que estavam sendo vigiados a transgredirem a lei e a ordem do lugar, mesmo que ela fosse opressora e contivesse a expansão da vida.

Atualmente, ainda segundo Deleuze (1992), encontramo-nos numa crise generalizada de todos os meios de confinamento, como a prisão, o hospital, a fábrica, a escola e a família. As sociedades de controle estão substituindo as sociedades disciplinares. Trata-se do con- trole a céu aberto, realizado por meio de formas ultrarápidas de controle ao ar livre que substituem as antigas disciplinas que operavam na duração de um sistema fechado. O homem da disciplina, explica o autor, era um produtor descontínuo de energia, mas o homem do controle é antes de tudo ondulatório, funcionando em órbita, num feixe contínuo. Enquanto as sociedades disciplinares tinham por equipamento máquinas energéticas, as sociedades de controle operam por máquinas de informática e computadores.

Para além das mensagens e dos agenciamentos veiculados pelos meios de comunicação, podemos observar que linguagens, valores, práticas, lógicas operacionais e modos de fazer característicos dos regimes de funcionamento das mídias estão cada vez mais presentes em nossas vidas cotidianas, engendrando novas formas de subjetividade. Entre elas, destacamos o homo videns, como propõe Giovani Sartori (2001), e/ou o homemtelevisão, como sugere Muniz Sodré (2002). E como seriam eles?

Para esses autores, seriam pessoas que parecem estar sempre diante das câmeras: sabem pra onde olhar, conhecem seu melhor ângulo, esboçam sempre um sorriso, medem as palavras, têm discursos e performances adequados para cada ocasião, cuidam muito bem da aparência, fazem tipos, têm cara de vitrine, funcionam como uma mídia ambulante e fazem de si mesmo um veículo para divulgar idéias e produtos.

Para Sartori (2001), o homo videns, inserido em uma sociedade que exalta o dever de mostrar tudo, desenvolve o desejo e/ou está sujeito à exigência de mostrar-se. Assim, ele produz cotidianamente pseudos-eventos, ou seja, fabrica eventos que acontecem somente porque há uma filmadora que os registra.

Muniz Sodré (2002), por sua vez, sugere que o homem-televisão é aquele que incorporou o código televisivo, passando a reger-se por suas regras quanto à aparência, atitudes e opiniões.

É nessa ambiência comunicacional, constituída pelas novas, e cada vez mais acessíveis, tecnologias da comunicação, pelos regimes semióticos das mídias e pelas suas lógicas operacionais, que tentamos compreender as contingências da produção de vídeos pornôs pelos adolescentes. 


\section{Flusser e a "Filosofia da Caixa Preta"}

Vilém Flusser (2002) define a imagem técnica como aquela que é produzida por apareIhos, como as máquinas fotográficas, as filmadoras, as câmeras de vídeo e as câmeras dos celulares. Segundo esse autor, o caráter aparentemente objetivo das imagens técnicas faz com que confiemos nela como confiamos em nossos próprios olhos. E quando fazemos críticas a elas, não o fazemos enquanto imagens, mas enquanto visões de mundo. Entretanto, ele adverte, entre as imagens técnicas e seus possíveis significados há um complexo aparelho-operador demasiadamente complicado para ser penetrado. Trata-se da "[...] caixa preta e o que se vê é apenas input e output [...]" (FLUSSER, 2002, p. 15).

Quem vê a caixa preta não vê o processo codificador que se passa em seu interior. Como não sabemos o que se passa dentro da caixa preta, somos analfabetos em relação às imagens técnicas e, portanto, não sabemos como decifra-las. Mesmo assim, assegura Flusser (2002), vivemos cada vez mais em função do que ele chama de magia imagética, ou seja, vivenciamos, conhecemos, agimos e atribuímos valor em função de tais imagens. Tal magia, contudo, é a ritualização de programas elaborados pelos fabricantes, visando nos programar para um comportamento mágico programado.

Se considerarmos os aparelhos produtores de imagens técnicas por esse prisma, o que lhe caracteriza é o estar programado. E, dessa maneira, as imagens que eles produzem estão previamente inscritas (programadas) por aqueles que fabricaram os aparelhos. Elas seriam, então, realizações de algumas das potencialidades inscritas no aparelho. 0 autor das imagens, fotógrafo ou cinegrafista, agiria em função da realização do universo fotográfico, cinematográfico ou videográfico. Seu interesse estaria mais voltado para esgotar as potencialidades do aparelho do que para o mundo lá fora.

Flusser (2002) define o fotógrafo/cinegrafista como um jogador que brinca não com mas contra seu brinquedo/aparelho. Não que ele esteja submisso ao aparelho, mas encontra-se em seu interior, amalgamado a ele. Nesse jogo, as potencialidades contidas no programa devem exceder a capacidade do operador de esgotá-la.

Esse sistema complexo e jamais penetrado totalmente é chamado pelo autor de caixa preta, na qual o fotógrafo/cinegrafista se perde, mas a qual, simultaneamente, consegue dominar, ao fazer funcionar o input e o output em função de suas intenções, fazendo-o cuspir imagens. Flusser considera que nesses aparelhos produtores de imagens e em seus operadores "[...] estão, como germes, contidas todas as virtualidades do mundo pós-industrial [...]" (FLUSSER, 2002, p.28).

De acordo com o autor, podemos observar na prática de fazer imagens a desvalorização do objeto/referente e a valorização da informação que elas transmitem. Assim, ele propõe que a análise do gesto de fotografar/filmar pode se constituir em um exercício para a análise da existência humana na sociedade pós-industrial, aparelhada, na qual tudo que é fotografável/filmável pode, e de deve, ser fotografado e filmado. A imagem, para Flusser produz antes de qualquer materialidade, informação, que realimenta o desejo de produzir/consumir mais imagens, no intuito de ter mais informação, seja sobre si, seja sobre o outro, ou sobre tudo aquilo que possa ser captado pelos aparelhos tecnológicos.

A fotografia enquanto objeto tem valor desprezível. Não tem muito sentido querer possuí-la. Seu valor está na informação que transmite. Com efeito, a fotografia é o primeiro objeto pósindustrial: o valor se transferiu do objeto para a informação. Pós-indústria é precisamente isso: desejar informação e não mais objetos. Não mais possuir e distribuir propriedades (capitalismo ou socialismo). Trata-se de dispor de informações (sociedade informática). Não mais um par de sapato, mais um móvel, porém, mais uma viagem, mais uma escola. Eis a meta, transformação de valores, tornada palpável nas fotografias. (FLUSSER, 2002, p. 47-48)

Pois bem, compreendidos alguns aspectos das contingências nas quais se co-engendram a compulsão em registrar tudo, ou quase tudo, em imagens, nos sentimos levadas a pensar o que mais poderia levar adolescentes a filmarem suas práticas sexuais e colocarem essas imagens nas redes. Essa interrogação nos levou, entre outras possibilidades, a discutir a questão da auto-apresentação. 


\section{Devires-Imagéticos e a Auto- Apresentação}

Conforme Gonçalves e Head (2009), o conceito devir-imagético, desenvolvido por eles no contexto da análise dos usos de imagens na pesquisa antropológica, busca mostrar a possibilidade de emergência de personagens que se apresentam e representam a partir de uma relação.

Para os autores, as mídias fotográficas, fílmicas, os vídeos-digitais e o imaginário imagético que elas animam fazem parte do corpo etnográfico-ciborgue que conecta a ciência ao mundo dos outros e às representações e apresentações que estes outros fazem de seus mundos e dos nossos mundos. As imagens, nessa perspectiva, são pensadas como formas de extensão de um suposto eu em direção a um suposto outro, como forma de relação, implicando a intersubjetividade, a multiplicidade, a performatividade e a encenação em meio as quais nos constituímos. Trata-se da ampliação da capacidade imaginativa, o que, segundo Gonçalves e Head (2009), possibilita outros modos pelos quais os indivíduos imaginam sobre si e sobre o outro, redefinindo a idéia de representação (na perspectiva do realismo) e abrindo caminho para a fabulação e a ficção ${ }^{3}$.

As imagens, fixas ou em movimento, são emblemáticas das conexões cada vez mais rápidas e diretas que constituem as comunidades transnacionais imaginadas do photo-capitalismo. Conforme os autores, a sensibilidade pós-industrial induz à proliferação das autorepresentações (no sentido de encenações, performances e experimentação de si) em que as culturas e os personagens se apresentam diretamente se fotografando, se filmando e falando de si em um diálogo contínuo com as múltiplas representações já constituídas sobre eles. Em meio a esses processos, engendramse curtos-circuitos políticos e estéticos que movimentam essas formas de representação e apresentação, e, assim, desestabilizam as verdades sobre as representações, fazendo emergir as fabulações dos personagens que se constituem nessa complexa relação.

3 Entendemos ficção por tudo aquilo que é inventado pelo homem, ou seja, tudo que é produzido na contingência da cultura.
A partir de suas leituras sobre o que Deleuze estabelece para a criação dos personagens no cinema, Gonçalves e Head (2009) sugerem que a função fabuladora aposta na evocação de uma potente falsidade sobre si, em oposição às verdades constituídas. Essa função fabuladora tem, portanto, a capacidade de criar uma lenda, de criar um monstro. Nessa perspectiva, o personagem criado não é real nem fictício, pois a auto-representação estaria aderida a uma formulação do devir da personagem real quando ela se põe a ficcionar, contribuindo para a invenção de si e de seu grupo.

Nesse processo de fabulação e produção de auto-imagem, são essenciais os intercessores, que são tudo aquilo que se coloca em relação, ou seja, todos os encontros que potencializam a criação, colocando as personagens em estado de ficcionar, de fabular, de fazer lenda.

Acreditamos que as noções de fabulação e de intercessores nos ajudam a compreender a os aspectos atuais e virtuais, práticos e imaginários, da constituição das formas de subjetividade e dos processos de subjetivação. Nesses processos relacionais, portanto, "[...] os cruzamentos de olhares e os efeitos indefinidos de reciprocidades [...]" (PIAULT apud GONÇALVES; HEAD, 2009, p. 23) estão no cerne da constituição das subjetividades. Ainda que as trocas sejam, necessariamente, inacabadas, desiguais, generalizadas e instáveis há um espaço permanente de intercomunicabilidade, no qual as abordagens de cada um tornam-se marcas inelutáveis de apropriação e diferenciação.

Seguindo esse pensamento, podemos pensar que os adolescentes que produziram os vídeos pornôs, não devem ser compreendidos como indivíduos totalmente autônomos em suas escolhas e performances, mas como personagens construídas na relação de produção das próprias imagens, portanto, personagens pré-individuais e trans-individuais, criadas a partir de fabulações e nas relações com seus intercessores, em processos de apropriação e diferenciação que se dão no contexto das sociedades de controle e dos universos videográficos constituídos pela programação dos aparelhos. Somos, como professores, importantes intercessores e, assim, na constituição dessas personagens constam também os modos pelos quais os representamos e os apresentamos, da mesma forma que os modos 
que nos representamos e nos apresentamos a eles. E a questão da sexualidade, como entra nessa complexa relação?

\section{Sexualidade, Escola e Vídeos}

A sexualidade, como política do sexo e como prática social, permeia e pulsa na vida dos jovens. Cada vez mais agenciados pelas mídias, o sexo, suas práticas, sua exigência e suas regulações são muitas vezes naturalizados ou ignorados pela escola. Em nossas pesquisas, pudemos observar que os jovens querem falar de sexo e, mais do que isso, querem que as questões relativas à sexualidade sejam temáticas curriculares. Para além das informações sobre reprodução e doenças sexualmente transmissíveis, eles querem falar sobre homossexualidade, infidelidade, frigidez, impotência sexual, sexo oral, sexo anal, aborto, masturbação e orgasmo, entre outras coisas.

Dificilmente esses assuntos fazem parte das aulas de educação sexual, quando elas existem. Professores e pedagogos, por sua vez, encontram-se num impasse que ultrapassa qualquer timidez, preconceito ou despreparo quanto à questão: o medo da reação das famílias, das autoridades educacionais e de possíveis processos judiciais a serem movidos contra eles.

Em sua pesquisa de doutorado numa escola municipal de Vitória, Soares (2009) incentivou os alunos da quinta a oitava série a escrever anonimamente em um papel os assuntos que gostariam que fossem discutidos na escola. A questão da sexualidade apareceu, disparado, em primeiro lugar. Na mesma pesquisa, a professora observou ainda que, quando perguntados sobre o que a aprenderam de importante dentrofora da escola, os jovens responderam que foi ter educação para ser alguém na vida, referindo-se, contudo, aos modos de conviver com os outros e não aos conteúdos específicos das disciplinas curriculares. Mas, porque tanto interesse, que para alguns pode parecer até exagerado e inadequado para a faixa etária dos alunos, pelo sexo e pela sexualidade?

Martín-Barbero (2004) considera que as mídias de massa, primeiro a televisão e depois, com muito mais intensidade a internet, produziram uma desorganização cultural à medida que proporcionaram às crianças e aos adolescentes o acesso a conteúdos antes considerados adultos e ocultados. Esse acesso a conteúdos adultos não se dava facilmente com os outros produtos da indústria cultural, como livros e brinquedos, cujos públicos foram segmentados pelo mercado. Pelos meios de comunicação, os jovens têm acesso ao que os pais fazem, ou estão passíveis de fazer, mas escondem deles, desmascarando uma prática que pode ser considerada hipócrita em uma sociedade na qual a ordem é mostrar tudo. O sexo, obviamente se inclui entre essas coisas possíveis de serem feitas e mostradas, o que, aliás, é reforçado com grande freqüência pelas mídias.

Já para Baudrillard (2001), mais do que uma possibilidade, o sexo tornou-se uma obrigação nas sociedades midiatizadas. Todos devem fazer sexo e, acima de tudo, obter satisfação com isso. A satisfação das necessidades é apontada como o principal, senão o único, caminho para a felicidade. Conforme esse autor, os vídeos pornográficos, facilmente encontrados nas locadoras, bancas de jornal e na internet, são exemplos das hiper-realidades que as mídias constroem, ou seja, realidades mais reais do que a realidade, pois podemos ver, em detalhes, o que não podemos ver com nossos próprios olhos quando protagonizamos tais cenas.

Talvez, o que mais tenha surpreendido no episódio noticiado não tenha sido o fato dos jovens terem feito sexo, uma vez que as pesquisas, constantemente divulgadas, apontam que a cada dia inicia-se mais cedo na vida sexual. Provavelmente, o que deixou muita gente estarrecida foi o fato deles terem gravado tais cenas e ainda por cima terem divulgado amplamente a gravação. Num contexto mais amplo, o que constitui a experiência de fazer um vídeo e o que ela possibilita?

O audiovisual, como afirma Rincón (2002, p. 10) é "[...] um supermercado simbólico de estilos de vida para habitar esses tempos desalmados de razões [...]" e, nesse universo de imagem e som, o vídeo é a "[...] tática para a aventura [...]" (RINCÓN, 2002, p. 10).

O autor propõe que as culturas audiovisuais, sem referência de território, juntam experiências instantâneas, sentimentais e narrativas produzindo estilos de habitar com formas inéditas de experiência, pensamento e imaginação. As culturas audiovisuais constroem 
um entorno que faz pensar com as imagens, engendrando uma paisagem-cultura-mundo audiovisual e tecnológica que brinda um repertório comum, a partir do qual se produz 0 sujeito contemporâneo. Ao mesmo tempo elas constroem uma paisagem-cultura-local de imagens e narrativas próximas e afetivas que reivindica as estéticas e as histórias localizadas como táticas legítimas de construção da subjetividade. As culturas audiovisuais, enfim, constituem os novos laboratórios experimentais da sensibilidade e do pensamento.

Sensibilidade é a idéia chave que Rincón (2002) desenvolve para a compreensão das formas audiovisuais. Trata-se, segundo ele, de um modo de expressão que se interessa pelo movimento, que estabelece novas relações e se dirige a um novo regime de reconhecimento e imaginação. Uma maneira de caracterizar este novo regime de sensibilidade seria pensála a partir das formas subalternas de inscrever a vida na atualidade: gênero, sexo, ecologia, etnia, juventude, música, futebol, telenovela, carnaval e classe, por exemplo.

As sensibilidades são, para o autor, perspectivas de produzir sentido que têm sido sistematicamente excluídas da verdade ocidental. Para ele, essas sensibilidades afirmam uma resistência afetiva-sensível, que desloca até o dramático e sentimental os âmbitos de produção e expressão do conhecimento, operando como táticas de um bufão que se atreve a incomodar as maneiras clássicas do saber e da cultura.

Assim, essas sensibilidades produzem novos modos de subjetividade, sem verdades transcendentais. Constituem novas valorações não escritas, memórias eletronicamente frágeis. O resultado, explica o pesquisador, pode ser compreendido como o império do banal e a anarquia como forma social, mas aí também seria possível se avistar uma luta por constituir-se.

Com Certeau (1994) aprendemos que os consumidores dos artefatos culturais não são passivos. Ao contrário, em suas práticas de usuários dos produtos, idéias ou processos que the são oferecidos ou impostos inventam outras possibilidades de existência. Essas táticas de usuários produzem desvios em relação às normas e constituem o cerne da vida social. Que pistas essas práticas desviantes nos apontam para pensarmos a educação que temos oferecido, a educação que os jovens almejam e as possibilidades para uma outra educação no contexto das sociedades capitalistas, globalizadas e midiatizadas?

\section{Algumas Considerações que Desdobram-se em Novas Problematizações}

Antes de mais nada, nos cabe interrogar porque esses vídeos chocam, ou ao menos causam espanto ou interesse, aos pais, professores, autoridades educacionais, órgãos do sistema judiciário, pesquisadores das ciências humanas e imprensa, considerando a quantidade de filmes desse tipo, criados e veiculados por não-profissionais, que circulam pela internet, principalmente se levarmos em conta a exigência de visibilidade total posta em nossos tempos e as condições propícias para que isso seja possível. É óbvio que, em se tratando de sexo, a idade dos autores/atores, por serem menores de 18 anos, é o primeiro motivo. Porém, para além disso, os vídeos pornográficos protagonizados e distribuídos pelos alunos, inclusive dentro da escola, desafiam e põem em xeque relações estratégicas entre saber, poder, educação, sexualidade, normalização e regulação da vida, especialmente, neste caso, dos adolescentes.

No nosso entender, vivemos na sociedade de controle, conforme analisada por Deleuze (1992), com todos os seus mecanismos de hiperexposição e modulação, mas sem termos deixado de lançar mão, especialmente no que refere à educação, de dispositivos característicos das sociedades disciplinares, principalmente no que diz respeito à normalização $e$ à regulação da sexualidade, não mais apenas com o objetivo de produzir corpos dóceis, submissos e produtivos, mas também porque naturalizamos a pedagogização da sexualidade da criança e do adolescente, assim como naturalizamos a moralidade que ela forja através dos mais variados discursos, inclusive aqueles produzidos pelas ciências humanas. Dessa forma, os vídeos produzidos pelos alunos ecoam como uma afronta às instituições (família, escola, ciência etc), evidenciando que elas estão irremediavelmente em crise.

Ao mesmo tempo, a contemporaneidade com suas novas tecnologias de comunicação e controle tornou mais abrangentes velhos mecanismos de disciplinarização como a su- 
perexposição dos corpos (já concebida com o panoptismo e ampliada com as câmaras que estão em todos os lugares) e a confissão, a obrigatoriedade de contar tudo, inclusive sobre a verdade do sexo, colocando-o em discurso. Gadelha (2009), a partir de seus estudos sobre a teorização de Foucault, nos fala sobre a intrincada relação entre o dispositivo da sexualidade e o dispositivo da disciplinarização:

Por um lado, a colocação do século em discurso, desde o século XVIII, passa a ser a estratégia ao tipo de poder que se exerce nas sociedades disciplinares, sendo assimilada, ou melhor agenciada ao dispositivo disciplinar; por outro lado, ao apoiar, relançar e modificar a colocação do sexo em discurso, bem como ao implantar e multiplicar sexualidades polimorfas, lançando mão de novos operadores e de um novo dispositivo (o da sexualidade), o (exercício do) poder também se transmuta, assumindo novos traços características, desdobramentos, funcionando como biopoder, dando ensejo à emergência de uma biopolítica, ao passo que as sociedades em que esses poderes se exercem também são transmutadas, transformando-se em sociedades de normalização e regulamentação. (GADELHA, 2009, p. 69)

Desde então, o sexo tornou-se assunto de interesse público e objeto de racionalização política, econômica e científica. Conforme Gadelha (2009), nas novas relações de dominação, a estratégia é fazer falar as sexualidades periféricas, ou seja, aquelas que fogem ao padrão estipulado pela conjugalidade burguesa e passam a ser inscritas sob a lógica da perversão demandando medidas educativascorretivas normalizadoras.

Nesse sentido, o que pode nos dizer essa produção de vídeos realizada por esses jovens, na qual levam ao extremo a instrumentalização da sexualidade, colocando o sexo em discurso (e em ato), valendo-se para isso da plasticidade que permite uma linguagem e uma mídia audiovisual? Estariam eles se produzindo, performaticamente, no registro da sociedade de controle, conforme às expectativas da contemporaneidade, ou, ao contrário, apostando na evocação de uma potente falsidade sobre si, em oposição às verdades constituídas para alçar um linha de fuga que, pelo excesso, possa estilhaçar os arranjos vigentes? Não podemos saber. Talvez eles mesmos não saibam. E a única resposta cabível seja: Tudo ao Mesmo Tempo Agora ${ }^{4}$.

De qualquer forma, o próprio Deleuze em um diálogo com Claire Parnet (2004) já advertia sobre os perigos de se instalar em linhas de fuga já criadas por outros, que podem levar, inclusive, à auto-destruição.

E seria um erro pensar que basta adotar finalmente a linha de fuga ou ruptura. Antes de mais é preciso traçá-la, saber como e onde traçar. E depois, ela própria tem o seu perigo, que é talvez o mais grave. Não somente as linhas de fuga, de maior inclinação, se arriscam a ser bloqueadas, segmentadas, precipitadas em buracos negros, como têm um risco particular adicional: transformarem-se em linhas de abolição, de destruição dos outros e de si próprio (DELEUZE; PARNET, 2004, p. 42).

É nesse sentido que consideramos ser necessário pensarmos a educação que temos oferecido, avaliando se com ela promovemos a regulação e a normalização da vida, despotencializando os jovens com o objetivo de fabricar subjetividades dóceis e submissas, bem como corpos produtivos como requer o capitalismo, ainda que não nos demos conta disso por termos naturalizado determinadas práticas e discursos. Dessa forma, e de modo a tentar evitar atitudes extremadas e possivelmente auto-destrutivas por parte de nossos alunos, devemos buscar compreender seus anseios por espaços de liberdade e criação e, com eles, traçar linhas de fuga afirmativas que engendrem outros modos de existir.

As tecnologias da comunicação não são boas nem más por si mesmas. E a forma como vamos viver daqui para a frente depende, em parte, dos usos que, juntos e colaborativamente, soubermos fazer delas. Da nossa parte, apostamos que alunos e professores têm o direito de ter acesso às novas tecnologias, de interagir por meio delas e com ela e, aprendendo uns com os outros, criar novas possibilidades para o conhecimento e para nossas existências. 


\section{Referências}

ADOLESCENTES Fazem Vídeo de Sexo e Distribuem na Escola. A Gazeta, Vitória, ES, p. 9, 21 maio 2009. BAUDRILLARD, J. Da Sedução. Campinas, SP: Papirus, 2001.

BAUMAN, Z. Medo Líquido. Rio de Janeiro: Zahar, 2008.

Certeau, M. de. Artes de fazer. In: Certeau, Michel de. A Invenção do Cotidiano. Petrópolis, RJ: Vozes, 1994. V. 1

DELEUZE, G. Conversações. Rio de Janeiro: Ed. 34, 1992.

DELEUZE, G.; PARNET, C. Diálogos. Lisboa: Relógio D’Água, 2004.

FLUSSER, V. A Filosofia da Caixa Preta: ensaios para uma futura filosofia da fotografia. Rio de Janeiro: Relume Dumará, 2002.

GADELHA, S. Biopolítica, Governamentalidade e Educação. Belo Horizonte: Autêntica, 2009.

GINZBURG, C. Mitos, Emblemas e Sinais: morfologia e história. São Paulo: Companhia das Letras, 1989.

GONÇALVES, M.A.; HEAD, S. Confabulações da Alteridade: imagens dos outros (e) de si mesmos. In: GONÇALVES, M.A.; HEAD, S. (Org.). Devires Imagéticos: a etnografia, o outro e suas imagens. Rio de Janeiro: 7Letras, 2009. Cap. 1.

GUATTARI, F. Caosmose: um novo paradigma estético. São Paulo: Ed. 34, 2000.

JENKINS, H. Cultura da Convergência. São Paulo: Aleph, 2009.

MARTÍN-BARBERO, J. Ofício de Cartógrafo: travessias latino-americanas da comunicação na cultura. São Paulo: Loyola, 2004.

RINCÓN, O. Televisión, video y subjetividad. Bogotá: Grupo Ed. Norma, 2002.

SARTORI, G. Homo videns: televisão e pós-pensamento. Bauru, SP: EDUSC, 2001.

SOARES, M. da C.S. A Comunicação Praticada com o Cotidiano da Escola: currículos, conhecimentos, sentidos. Vitória, ES: Espaço Livros, 2009.

SODRÉ, M. Antropológica do Espelho: uma teoria da comunicação linear e em rede. Petrópolis, RJ: Vozes, 2002.

Recebido em março de 2010.

Aprovado para publicação maio de 2010.

\section{Conceição Soares}

Jornalista, Pós-Doutoranda em Educação do Programa de Pós Graduação da Universidade do Estado do Rio de Janeiro (PROPED/UERJ). Bolsista do convênio FAPERJ/CAPES. Rio de Janeiro-RJ/Brasil.

Email: ceicavix@gmail.com

Vanessa Maia

Jornalista, Doutoranda em Educação pelo Programa de Pós Graduação da Universidade Federal do Espírito Santo (PPGE/ UFES). Vitória- ES/Brasil. Email: vanesssamaia@gmail.com 